\title{
Support for innovative fast growing companies as an element of sustainability of the Russian financial system
}

\author{
Yulia Darina ${ }^{1}$, and Ivan Daurtsev ${ }^{1, *}$ \\ ${ }^{1}$ Federal State Autonomous Educational Institution for Higher Professional Education National \\ Research University Higher School of Economics, 101000, Myasnitskaya str., 20, Moscow, Russia
}

\begin{abstract}
The crisis phenomena on the hydrocarbon, gas and other raw materials market make it necessary to search for new points of growth of the national economy in order to ensure the stability of the financial system to external factors. An increase of the population of fast growing companies, the growth rate of which can be intensified through interaction between business and the state is one of the effective mechanisms for overcoming resource dependences. The article discusses the mechanism of interaction of the business community with scientific organizations using budgetary funds, which has positively established itself in foreign markets, in Russia. The authors also examined the regional aspect of state support for such cooperation. However, according to the conducted research, this mechanism does not bring positive results because of some administrative barriers, such as extremely high level of accountability, low-effective control system and transfer of foreign technologies.
\end{abstract}

\section{Introduction}

In the context of crisis on the market of hydrocarbons, gas and other raw materials that underlie the economy of the Russian Federation, and the deterioration of international relations, it seems necessary to look for new points of growth of the national economy in order to ensure the sustainability of the financial system to external factors.

In such conditions, the most comprehensive measure is the accelerated development of innovations. The application of various models of innovation support can solve the related problems, such as stable GDP growth, the sustainability of companies' development, and an improvement in the investment climate. At the same time, significant economic growth can be achieved through small and medium-sized fast growing business, which occupies a leading position in its market niches.

More than half a century of research shows that the phenomenon of sustainable and long-term growth is manifested in fast growing companies that positively influence the dynamics of the country's economic development and allow stabilizing the financial system of the state. Such companies are not only aimed at a significant increase in GDP, but also at creating new jobs. In the economy of most countries, it is possible to single out individual

\footnotetext{
*Corresponding author: ivan.daurtsev@gmail.com
} 
companies, the revenues of which constitute a significant share of GDP. In this case, the phenomenon of sustainable long-term growth manifests itself only in a small percentage of companies - the fast-growing businesses ("gazelles") [2].

Foreign experience of support and development of fast growing companies shows that one of the most important conditions for the successful development of high-tech sectors of the economy is the interaction of organizations of the real sector of economy with scientific organizations, including higher educational institutions that allow creating, transferring and introducing new knowledge and technologies into production. At the same time, an important role in the interaction of companies and scientific organizations is played by the state, which should stimulate and support such cooperation. It is seen necessary to focus attention not only on the scale of interaction, but also on the need to improve the quality and prevalence of such processes [2-7].

The cooperation between the Eindhoven University of Technology and the Avans University of Applied Sciences resulted in the creation of one of the leading technological hubs. To date, such a cluster registers more than $50 \%$ of patents in the Netherlands, and also attracts about a third of investments in research and development [7].

In addition, the transfer of technology between the academy and applied industrial R\&D enabled the construction of a powerful innovative system of Israel, through which the country was able to become one of the most innovative world economies. It is worth noting effective state support for such transfers through stimulating the development of applied $\mathrm{R} \& \mathrm{D}$ with programs, in the framework of which it is more profitable for the business community to cooperate with the state than to compete with it in the sphere of development [12].

Besides, foreign studies show that an increase in the population of fast growing firms should be based on the support delivered by regional and local authorities in order to identify market niches for more sustainable growth of companies [6].

Thus, increasing activity in research and development, and their interaction with business entities, in particular, with fast growing companies is one of the effective ways to overcome current problems in Russia, as well as to enhance the stability of the state financial system.

The purpose of the study is to test the hypothesis on the existence of a relationship between the activity of the regions in supporting innovative cooperation of scientific organizations and the development of fast growing companies.

\section{Materials and methods}

In recent years, the Russian government has been actively implementing measures of selective support for leading universities, research institutes and individual research groups. In addition, in the developed countries the institutional factor significantly affects the innovation of production and processes in enterprises. In this connection, a database of the state support measures for leading Russian universities and research teams was compiled within the framework of the research.

This database contains information on the implementation of the following measures of the state support:

- Establishment of national research universities;

- Creation of federal universities;

- Development of cooperation between Russian universities and industrial enterprises in accordance with the Decree of the Government of the Russian Federation of April 9, 2010 No. 218;

- State support of innovative infrastructure of universities in accordance with the Decree of the Government of the Russian Federation of April 9, 2010 No. 219; 
- Attraction of leading foreign scientists in accordance with the Decree of the Government of the Russian Federation of April 9, 2010 No. 220;

- Grants of the Russian Science Foundation;

- Grants of the Skolkovo Foundation.

It should be noted that the database did not include projects supported by the Russian Foundation for Basic Research (RFBR) in connection with the restricted access to the library's materials. According to the data on the official website of the Foundation, RFBR publishes newsletters on the results of the competitions, but there is no opportunity to analyze such information through electronic means.

Also, it is worth mentioning that the site contains information on the supported projects for each competition separately, but this information is not enough to conduct analysis for the purposes of our research.

Thus, 1304 projects were included in the database, which were implemented within the framework of the above support measures. Such projects were distributed among the constituent entities of the Russian Federation, on the territory of which such a project was implemented.

To check the relevance and results of the projects implementation, a database of projects that received support under the federal targeted programs was used. At the same time, some of the projects within the framework of measures stipulated by the Government of the Russian Federation Decrees No. 218-220 have not been implemented, despite the fact that they became winners of the contest. The implementation of the projects was tracked with the help of the project "Expir". Such a project has been functioning since 2013 with the support of the Ministry of Education and Science of the Russian Federation and the Directorate of Scientific and Technical Programs [14].

It should be noted that the staff of the project "Expir" confirm the experts' conclusions about the lack of communication between the subjects of the innovation ecosystem in Russia.

To analyze the relationship and the impact of these values, the Pearson correlation coefficient was calculated, and multiple regression analysis was performed.

Before proceeding with the construction of the regression model, the influence of the following control variables was analyzed in the context of regions reflecting their social and economic conditions, the development of infrastructure for doing business, and their scientific potential, as on the beginning of 2013.

To assess the effect of these parameters, the correlation coefficients for each of them with the share of fast growing companies were calculated. The results of this calculation are presented in the Table 1.

Table 1. Correlation coefficients (compiled by the authors).

\begin{tabular}{|l|c|}
\hline \multicolumn{1}{|c|}{ Indicator } & Correlation coefficient \\
\hline GRP per capita & 0.398933992 \\
\hline Unemployment rate & -0.40693546 \\
\hline Investments in fixed assets & -0.04818 \\
\hline Average per capita cash income of the population & 0.401948 \\
\hline Human development index & 0.203947 \\
\hline Consumer spending per capita on average & 0.08199 \\
\hline Density of railways at the end of the year & 0.175407 \\
\hline Specific weight of paved roads in the total length of public roads & -0.08212 \\
\hline Number of staff engaged in research and development & -0.0849 \\
\hline Number active subscribers of fixed broadband Internet access & -0.1169 \\
\hline Total area of living space per person on average & 0.52015 \\
\hline
\end{tabular}




\begin{tabular}{|l|c|}
\hline $\begin{array}{l}\text { Number of professional educational organizations engaged in the } \\
\text { training of skilled workers and employees }\end{array}$ & $-0,08706$ \\
\hline $\begin{array}{l}\text { Number of students enrolled in undergraduate and graduate } \\
\text { programs and magistracy per 10000 people }\end{array}$ & -0.03147 \\
\hline Internal costs for research and development & -0.05856 \\
\hline Number of submitted patent applications & -0.05267 \\
\hline Number of patents granted & -0.05532 \\
\hline
\end{tabular}

Based on the results of the analysis of the indicators, control variables were selected that have a significant influence on the dependent variable (the share of fast growing companies). Thus, for the analysis, the following independent variables are selected:

- GRP per capita;

- Unemployment rate;

- Average per capita cash income of the population;

- Total area of living space per person on average.

It should be noted that in the analyzed parameters, there is a moderate correlation with the share of "gazelles", with the exception of the last indicator. Analyzing these indicators, we can conclude that the socio-economic conditions of the region, as well as infrastructure development have a greater impact on the number of fast growing companies.

\section{Results}

First of all, it seems expedient to determine the interrelation of all the chosen measures to support scientific organizations with the spread of the number of "gazelles". For this purpose, the Pearson correlation coefficient was calculated, which determines how proportional the variability of these variables is. The results of calculating the correlation coefficient are presented in the Table 2.

Table 2. The results of calculating the correlation coefficient. $\S \S \S \S$

\begin{tabular}{|c|c|c|c|}
\hline & & 5 & $\begin{array}{l}\text { The share of } \\
\text { "gazelles" }\end{array}$ \\
\hline \multirow[t]{3}{*}{5} & Pearson's correlation & 1 &,- 100 \\
\hline & Values (two-sided) & &, 370 \\
\hline & $\mathrm{N}$ & 84 & 83 \\
\hline \multirow{3}{*}{$\begin{array}{l}\text { Share of } \\
\text { "gazelles" }\end{array}$} & Pearson's correlation &,- 100 & 1 \\
\hline & Values (two-sided) &, 370 & \\
\hline & $\mathrm{N}$ & 83 & 83 \\
\hline
\end{tabular}

There is a very weak, insignificant negative relationship between the variables.

After analyzing the dependence of the variables, a regression analysis was performed. The Table 3 presents the results of regressions using significant variables.

In Lines 1-4, the explanatory variables include the number of subjects receiving each of the types of support measures in the region:

- Creation of national research and federal universities - line "1";

- Development of innovative infrastructure of universities and innovative cooperation in accordance with Government Decisions No. 218-220 - line "2";

- Grants of the Skolkovo Foundation - line "3";

- Grants of the Russian Science Foundation - line "4".

It should be noted that the number of entities receiving government support in the region was chosen as a variable due to the lack of some data on the amount of funding in the public domain. 
After the regression analysis, it can be concluded that the selected measures of state support to scientific organizations do not have a statistically significant impact on the share of fast growing companies. This indicates a low effectiveness of the application of such measures, as well as weak cooperation of the business community with Russian scientific organizations. However, one should not overlook the possibility of using foreign technologies by the companies. The results of the regression analysis are presented in the Table 3.

Table 3. Results of the regression analysis.

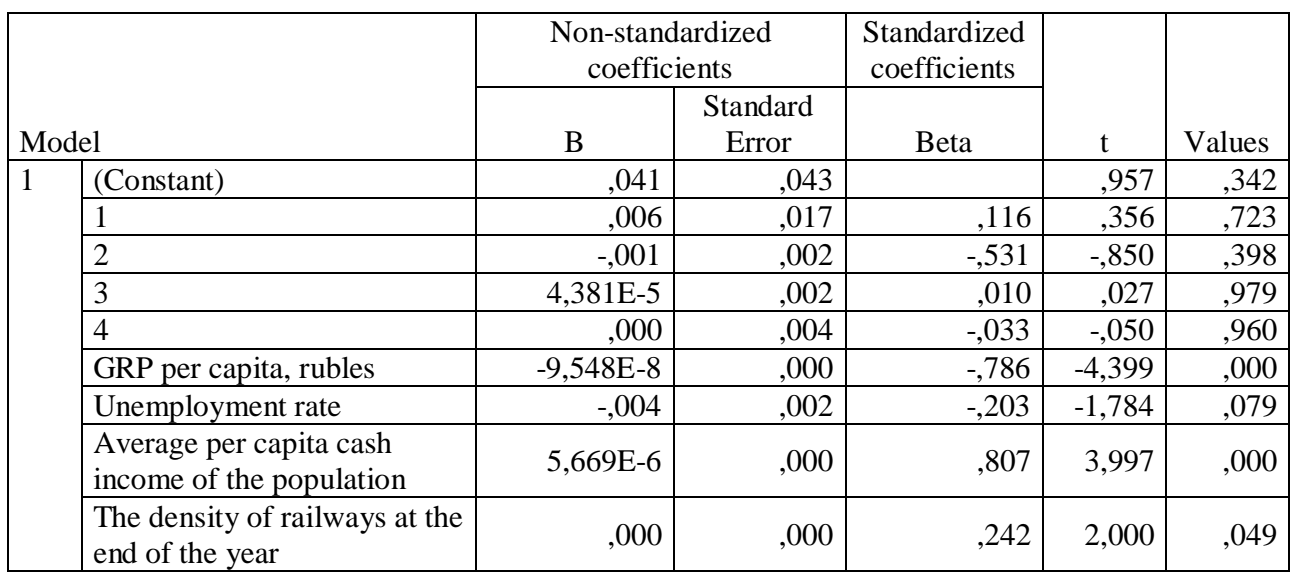

a. Dependent variable: Share of "gazelles"

Summary for the model

\begin{tabular}{|l|r|r|r|r|}
\hline Model & R & R-square & \multicolumn{1}{c|}{$\begin{array}{c}\text { Corrected R- } \\
\text { square }\end{array}$} & $\begin{array}{c}\text { Standard } \\
\text { estimation error }\end{array}$ \\
\hline 1 &, $613 \mathrm{a}$ &, 376 &, 308 &, 05869557688023 \\
\hline
\end{tabular}

a. Predictors: (constant), density of railways at the end of the year, average per capita cash income of the population, unemployment rate, GRP per capita, rubles, 3, 2, 4.

The coefficient of determination is 0.376 , which means that the calculated model parameters explain the relationship between the selected parameters only by $37.6 \%$. None of the selected parameters of the regression model is significant. Consequently, the results of such an analysis should not be considered significant.

Thus, hypothesis 1 is not confirmed, and hence the cooperation of the scientific organizations and the business community in the Russian Federation is ineffective. In addition, despite the positive foreign practice, the selected measures of state support do not contribute to an increase in the population of fast growing organizations introducing innovations in their products, as well as modernization processes in production.

In addition, it should be noted that most entrepreneurs refuse to receive state support because of the complexity of the bureaucracy. Also, the provision of reporting for the use of budgetary funds is a problem for business entities, the goal of which is not being dependent on the state. Entrepreneurs also distinguish one more barrier - the low speed of interaction between the government bodies and business entities.

The complexities of administrative procedures, which have a negative effect on the activity of entrepreneurs in terms of using state support mechanisms and, consequently, on the implementation of innovations, should be considered a disadvantage, since often R\&D costs are prohibitive for business. So, the norm of the Civil Code (clause 1 of the Article 
185.1) on the need for a notarized power of attorney has practically stopped the electronic submission of applications [1].

It should also be noted that it is impossible to assess the effectiveness of the existing mechanisms of state support for innovative entrepreneurship, not only because of the lack of knowledge among entrepreneurs about possible tools, but also the lack of data that would allow assessing the results and effectiveness, for example, of tax benefits. In the open data, there is no information on accounting of the shortfall in budget revenues that arise with the provision of tax benefits. In this regard, it is impossible to assess the effectiveness of the application of tax incentives for innovative entrepreneurship.

\section{Conclusion}

The phenomenon of fast growing companies has been studied by scientists for more than 50 years. Such companies make a significant contribution to the country's financial system. In recent years, in Russia, the development of "gazelles" has been stimulated through state support, but the types of such support are extremely restrained. Targeted support is provided through information interaction between business and the state. At the same time, scientific organizations are not included in such a scheme, and they do not contribute to the development and implementation of innovations to increase the share of fast growing companies.

The development of such companies directly depends on the availability of regional natural resources, the right choice of the market niche, the resources for developing and implementing innovations, and the introduction of modernization processes in production. Besides, constraints on development also arise on the way of implementing projects that can be eliminated through the effective management of the "gazelle" strategies. Foreign studies show that the availability of financial resources has an impact on the favorable development of such companies that directly depends on the government policy promoting the improvement of the business environment.

It should be noted that subsidies are the most common type of support for innovative entrepreneurship in Russia. At the same time, state support through foundations is realized for specific projects of scientific organizations that cannot testify the introduction of research and development into batch production. In this connection, it is not possible to define such a policy as effective. This indicates a weak level of the technology transfer. Taking into account that such a transfer allows creating a strong innovative system, it is necessary to pay attention to the cooperation of scientific organizations with the business community. Taking into account the results of the analysis, reflecting the greater efficiency of the own financial resources than the public funding of research and development, public policy should stimulate the use of the companies' own funds through indirect support methods.

Analysis of the activity of fast growing companies in Russia shows that most often such companies are found in the manufacturing and construction industries that can be explained by the sanctions imposed on the Russian Federation import.

Herewith, the largest share of fast growing companies in the manufacturing industry belongs to the food production sector that confirms the previous conclusion, and may also be the result of the active state policy in supporting agriculture. Also, a high proportion of the population of "gazelles" is met in the branches of repair and installation of machinery and equipment, the production of finished metal products, and the production of chemical products. Based on the available open data referring to the activities of fast growing companies, it is not possible to make an unambiguous conclusion about the stability of the growth of such companies through the development and application of innovations, which would permit obtaining a stable contribution to the financial system of Russia. 
The analysis of the activity of fast growing companies in the regional context allows concluding that the largest share of such companies is found in regions with a high natural resource potential due to rich mineral deposits and favorable climatic conditions for the development of food production sectors. The development of fast growing companies in the region is affected by the solvency of the population that allows them to raise their own funds in production and support the steady growth of such companies. However, we should pay special attention to the infrastructure, and, in particular, to the transport accessibility of production in order to minimize the transport costs of a number of subjects for the marketing innovative products.

Despite the confirmed effectiveness of the use of technology transfer between the scientific and business communities in foreign countries, the studied measures of state support for the scientific organizations do not have a statistically significant impact on the share of fast growing companies in Russia. In this connection, it can be assumed that "gazelles" to a greater extent use foreign technologies. Undoubtedly, the results of the analyzed measures to support scientific organizations cannot be fully considered as the key measures for the introduction of developments in production.

Specifically, we should pay attention to the closeness of information on the developed results, as well as the multiplicative effect of the implementation of such projects. With the help of the database of the supported projects, we have managed to conclude that about a quarter of projects are not supported at the final stage of their implementation. This can be explained by an excessively large number of necessary documents and accountability for the development of budgetary funds [17].

Thus, one can draw a conclusion about the peculiar nature of fast growing companies in Russia, as well as about the need for a comprehensive study of the principles of building and functioning of the national innovation system, based on the transparency of the selection mechanisms for the supported projects and the construction of a technology transfer system between scientific organizations and enterprises.

The need for these actions to establish a national innovation system is also conditioned by the events taking place on the international arena and imposing restrictions on the activities of the Russian companies. In this regard, the state support for innovative projects should be a priority when implementing the policy of import substitution. The implementation of such a policy will help to avoid the resource dependence of the Russian budget.

\section{References}

1. The Civil Code of the Russian Federation, No. 51-FL (Moscow, 1994)

2. Z. J. Acs, W. Parsons, S. Tracy, Small Business Administration Office of Advocacy Working Paper, 328 (2008)

3. INNOVA Gazelles Innovation Panel, 6 (2008)

4. M. Deschryvere, Research Institute of the Finnish Economy Discussion Paper, 1144 (2008)

5. C. C. Gallagher, M. J. Daly, J. C. Thomason, Small Business Economics, 3, 4 (1990)

6. C. Mason, R. Brown, Small Business Economy, 40, (2013)

7. V. Pereira, Y. Temouri, Management Decision, 56, 1 (2018)

8. A. V. Gribovsky, Science, Innovations, Education, 18 (2015)

9. S. P. Zemtsov, V. A. Barinova, A. V. Sorokina, The Russian Entrepreneurship, 16, 22 (2015) 
10. N. V. Zubarevich, SPERO, Social Policy: Expertise, Recommendations, Reviews, 10 (2009)

11. N. P. Makasheva, Bulletin of Tomsk State University - Economics, 3, 23 (2013)

12. D. Maryasis, Experience in building the economics of innovation: the case of Israel (Institute of Oriental Studies, Moscow, 2015)

13. Yu. A. Polunin, A. Yu. Yudanov, The World of New Economy, 2 (2016)

14. The project "Expir" (www.xpir.ru)

15. The Russian Venture Company (www.rusventure.ru)

16. The Russian Foundation for Basic Research (http://www.rfbr.ru/rffi/ru)

17. E. Borisov, Forbes (http://www.forbes.ru/tehnologii/343245-startapy-suniversitetskoy-skami-pochemu-v-rossiyskih-vuzah-ne-razvivayutsya) 